\title{
UM BANHO DE CIDADANIA NAS MARGENS DO CÓRREGO SÃO JOÃO
}

\section{A BATH OF CITIZENSHIP IN THE EDGES OF THE SÃO JOÃO STREAM}

\author{
Daniela Franco Carvalho Jacobucci ${ }^{1}$ e Giuliano Buzá Jacobucci ${ }^{2}$ \\ ${ }^{1}$ Universidade Federal de Uberlândia - UFU/Instiuto de Biologia; Programa de Pós-graduação em \\ Educação-FACED/UFU, 38400-902 - Uberlândia - MG - Brasil, danielafcj@inbio.ufu.br \\ ${ }^{2}$ Universidade Federal de Uberlândia - UFU/Instituto de Biologia, CEP: 38400-902 - Uberlândia - MG - \\ Brasil, jacobucci@inbio.ufu.br
}

\section{RESUMO}

Essa pesquisa investigou o desenvolvimento coletivo de um projeto de Educação Ambiental extracurricular com alunos de Geografia no Ensino Médio. O tema gerador foi "Lixo no Córrego São João", um afluente do Rio Jaguari-Mirim em São João da Boa Vista - SP. Foram realizadas sete etapas: seleção dos pontos do córrego para a ação educativa; observação dos resíduos sólidos presentes no córrego; produção de material informativo e orientação aos moradores; nova observação dos resíduos sólidos no córrego pós-intervenção junto aos moradores; avaliação geral do projeto; e elaboração do relatório final. Não houve redução aparente da quantidade e dos tipos de resíduos sólidos lançados ao córrego, pelos moradores do entorno, após a atividade educativa. No entanto, o projeto tornou-se palco para que os alunos vivenciassem a problemática ambiental in loco, estabelecessem relações entre meio ambiente e sociedade, e se percebessem como cidadãos pertencentes a uma coletividade e a uma realidade complexa.

Palavras-chave: educação ambiental, lixo, construção coletiva, ensino médio, ensino de Geografia.

\begin{abstract}
This research investigated the collective development of an Environmental Education extra-curricular project with high school students of Geography. The generating subject of the project was "Garbage in the São João stream", a tributary of Jaguari-Mirim river in the city of São João da Boa Vista, inland of São Paulo state. Seven stages had been carried through: selection of stream sites for the educative action; observation of the solid residues present in the stream; production of informative material and orientation to the inhabitants; new observation of the solid residues in the stream after intervention with the inhabitants; general evaluation of the project; and elaboration of the final report. There was no apparent reduction of the amount and the types of solid residues launched to the stream, by the neighboring inhabitants, after the educative activity. However, the project became a stage for the students to live the environmental problematics in loco, establishing relations between environment and society, and seeing themselves as citizens belonging to a collectivity and to a complex reality.
\end{abstract}

Keywords: environmental education, garbage, collective construction, high school, geography education 


\section{EDUCAÇÃO AMBIENTAL E CIDADANIA}

A relação entre meio ambiente e Educação para a cidadania assume um papel cada vez mais desafiador, demandando a emergência de novos saberes para apreender processos sociais que se complexificam e riscos ambientais que se intensificam (JACOBI, 2003).

Para Guimarães e Vasconcellos (2006), o pressuposto básico de uma Educação Ambiental Crítica é a abordagem interdisciplinar, referenciada na perspectiva da complexidade e subsidiada pela interpretação histórico-crítica da realidade, o que evidencia o caráter participativo, permanente e político da dimensão ambiental no processo educativo.

Segundo Ferreira e colaboradores (2002), a cidadania ativa decorre do sentimento de pertença dos indivíduos e dos grupos à sociedade em que se inserem e, por isso, depende também da promoção de condições de inclusão social, bem como do desenvolvimento de atitudes e valores.

Apesar da problemática ambiental estar sendo veiculada constantemente pela mídia e o tema meio ambiente ser abordado nas escolas seja de forma curricular, como tema transversal ou extra-curricular, poucos estudos focam os jovens como potenciais mediadores dessa temática na sociedade, através de uma formação cidadã. Uma pesquisa sobre o perfil da cidadania ambiental ${ }^{1}$ com jovens do Ensino Médio-técnico, de classe média, revelou que a metade dos estudantes admite que os assuntos relacionados ao meio ambiente não vêm sendo tratados com freqüência nas escolas, bem como também não é abordado no âmbito das famílias. A maioria dos alunos não acessa sites ligados à temática ambiental e não acredita na eficácia da ação dos órgãos normativos de controle ambiental, e ainda, uma parte dos alunos não acredita no trabalho das Organizações Não-Governamentais Ambientalistas (FERNANDES et al., 2006).

A Educação como um todo, e o Ensino de Geografia em particular, deveria proporcionar o desenvolvimento da cidadania para uma participação mais efetiva na busca de políticas ambientais mais justas. Os problemas sociais, ora são deixados de lado completamente, ora são ressaltados, mas sem uma contextualização históricoespacial. Muitas vezes, desconsidera-se também a base física material, onde se interpenetram espacialmente as relações sociais. Esse ponto é de grande importância

\footnotetext{
${ }^{1}$ Para um aprofundamento nesse tema vide Silva-Sánchez (2000). 
para a discussão da Educação Ambiental, pois esta, ao apontar para a necessidade de uma educação criativa, capaz de formar o cidadão, deve considerar o conhecimento das diferenças culturais e buscar melhores condições de vida para as populações, apontando uma mudança paradigmática do saber. Tal mudança deve permitir passar de uma visão que dicotomiza e fragmenta a realidade, para a produção de novos conhecimentos e práticas escolares e de valores consubstanciados numa relação dialógica entre professor e aluno e todos os agentes escolares (BORTOLOZZI e PEREZ FILHO, 2000).

Este trabalho aborda o tema meio ambiente vinculado à disciplina de Geografia e buscou envolver jovens estudantes em um projeto de Educação Ambiental, visando a participação coletiva e democrática para a interpretação da realidade.

\section{PREPARAÇÃO PARA O BANHO}

A professora responsável pela disciplina de Geografia da $1^{\mathrm{a}}$ série do Ensino Médio de um colégio privado na cidade de São João da Boa Vista, Estado de São Paulo, sugeriu aos seus 22 alunos um trabalho em equipe para o desenvolvimento de atividades de Educação Ambiental. Como os alunos se mostraram favoráveis à proposta ${ }^{2}$, a professora solicitou a colaboração de uma pesquisadora universitária graduada em Ciências Biológicas para delineamento do estudo.

Inicialmente, a pesquisadora universitária discutiu com a professora de Geografia a motivação para a realização das atividades extracurriculares de Educação Ambiental, as possibilidades de envolvimento dos alunos em ações voluntárias em horários não-escolares e as implicações logísticas de um trabalho extra-classe com alunos menores de idade.

Como a professora se mostrou muito interessada em desenvolver um trabalho diferente e afirmou que as questões de ordem prática poderiam ser resolvidas facilmente com a direção da escola, foi marcada uma conversa com os alunos para sondar as idéias de atividade que eles tinham e gostariam de pôr em prática.

$\mathrm{O}$ encontro da pesquisadora com os alunos foi mediado pela professora, que procurou incentivar a participação dos mesmos e informar sobre o papel da pesquisadora na atividade. Todas as sugestões e colocações dos alunos foram registradas na lousa, no intuito de configurar um panorama de idéias.

\footnotetext{
${ }^{2} \mathrm{O}$ projeto foi desenvolvido no período de outubro a dezembro de 2001.
} 
Os alunos enfatizaram que gostariam de fazer algo concreto em Educação Ambiental, fora da sala de aula. Como a professora colocou que a atividade extracurricular seria avaliada na disciplina, por meio de um relatório em grupo, enfatizou-se a necessidade de elaboração de uma proposta que pudesse ser passível de análise. Assim, chegou-se a um consenso que seria necessário conceber a atividade como um projeto, com fases de preparação, realização e avaliação.

Posto isso, partiu-se para uma segunda etapa de discussão, relativa ao foco do projeto, ao problema que seria estudado. Os alunos apontaram diversos problemas sócio-ambientais, alguns que já haviam sido abordados formalmente na disciplina de Geografia, e outros novos, oriundos de informações adquiridas na mídia e no convívio familiar. Após esses relatos, a maioria dos alunos se mostrou favorável a trabalhar o tema lixo. Durante a conversa, a pesquisadora questionou os alunos sobre essa definição: De qual lixo estamos falando? Lixo doméstico? Lixo hospitalar? Jogar lixo no chão? Lixo que pode ser reciclado? Com isso os alunos perceberam que o tema ainda era muito amplo para o projeto.

Uma das alunas colocou que gostaria de trabalhar sobre os problemas causados pelo lixo jogado no rio, visto que a cidade possui o Córrego São João ${ }^{3}$ que atravessa vários bairros. Nesse momento, vários outros alunos se animaram com a idéia e começaram a contar histórias de enchentes, doenças e situações de risco decorrentes dessa problemática. Após a definição da temática do projeto, a pesquisadora estimulou os alunos a formarem grupos e a pensarem mais especificamente sobre o problema que eles gostariam de responder com o projeto: O que vocês querem fazer com o projeto? Saber o quê do lixo que é jogado no rio? Qual problema vocês querem focar? O que vocês querem verificar?

Essa etapa foi mais difícil de delinear de forma conjunta com os alunos porque, geralmente, os trabalhos escolares são requisitados com um tema-problema já estabelecido e dessa forma os alunos não têm experiência sobre a realização de um projeto e muito menos sobre a necessidade de levantamento de uma pergunta para esse projeto. Tendo isso em vista, a pesquisadora optou por sugerir alguns exemplos sobre o que poderia ser uma questão: Casos de enchente em São João da Boa Vista em função do lixo urbano em vias públicas; Lixo no Córrego São João - quem joga e o que pode

\footnotetext{
${ }^{3}$ O Córrego São João é um afluente do rio Jaguari-Mirim, cuja nascente está localizada no Estado de Minas Gerais. 
ser feito; O que pensam os moradores do entorno do Córrego São João sobre o lixo no rio?

Os alunos e a professora optaram em desenvolver a questão do lixo no Córrego São João para investigar quem joga esses resíduos no rio e discutir o que poderia ser feito a respeito, sob a perspectiva da Educação Ambiental. Dessa forma, foi agendado um novo encontro com os alunos para delinear o projeto. A pesquisadora solicitou que durante uma semana os alunos pensassem na atividade que gostariam de desenvolver e que os grupos trouxessem sugestões do que poderia ser realizado.

No segundo encontro, os grupos relataram suas sugestões de atividades. A maioria dos alunos foi unânime em propor uma fase de investigação para saber os tipos e quantidade de resíduos sólidos no Córrego São João e uma fase de intervenção, que seria baseada na elaboração de panfletos sobre o problema e distribuição aos moradores. A pesquisadora procurou relacionar as sugestões de atividades à questão definida anteriormente e discutir as propostas com os alunos. Foi montado um cronograma das atividades (Quadro 1), com descrição do objetivo geral do projeto, definição das etapas do projeto, e o que deveria ser realizado e avaliado em cada etapa. Todas as sugestões dos alunos foram negociadas coletivamente para a integração ou não ao cronograma.

Quadro 1: Cronograma de atividades do Projeto de Educação Ambiental

\begin{tabular}{|c|c|c|}
\hline \multicolumn{3}{|c|}{ Projeto de Educação Ambiental: Lixo no Córrego São João } \\
\hline \multicolumn{3}{|c|}{$\begin{array}{c}\text { Objetivo Geral: Investigar os resíduos sólidos presentes no Córrego São João, em São João } \\
\text { da Boa Vista - SP; Desenvolver uma atividade de Educação Ambiental com os moradores } \\
\text { próximos ao córrego; Avaliar se ocorreu mudança em relação aos resíduos sólidos após a } \\
\text { atividade educativa. }\end{array}$} \\
\hline Etapas & Desenvolvimento & Avaliação \\
\hline $\begin{array}{l}\text { A) Determinação dos } \\
\text { pontos do córrego e } \\
\text { preparação para as visitas }\end{array}$ & $\begin{array}{l}\text { Definir os pontos a partir do } \\
\text { mapa da cidade e preparar } \\
\text { todos os grupos para as visitas. }\end{array}$ & $\begin{array}{l}\text { Checar se os pontos foram } \\
\text { definidos. }\end{array}$ \\
\hline $\begin{array}{l}\text { B) Investigação sobre os } \\
\text { tipos e quantidade de } \\
\text { resíduos sólidos presentes } \\
\text { nos pontos definidos }\end{array}$ & $\begin{array}{l}\text { Realizar duas visitas, em } \\
\text { sábados consecutivos pela } \\
\text { manhã, nos pontos definidos, } \\
\text { sendo cada equipe responsável } \\
\text { por um ponto. }\end{array}$ & $\begin{array}{l}\text { Verificar se todas as equipes } \\
\text { fizeram as visitas e se } \\
\text { anotaram os tipos e } \\
\text { quantidades de resíduos } \\
\text { sólidos no córrego. }\end{array}$ \\
\hline $\begin{array}{l}\text { C) Elaboração de material } \\
\text { informativo para os } \\
\text { moradores }\end{array}$ & $\begin{array}{l}\text { Elaborar um material } \\
\text { informativo para distribuição e } \\
\text { orientação aos moradores. }\end{array}$ & $\begin{array}{l}\text { Checar se o material } \\
\text { informativo foi confeccionado } \\
\text { e reproduzir para distribuição. }\end{array}$ \\
\hline $\begin{array}{l}\text { D) Distribuição do } \\
\text { material informativo e } \\
\text { orientação aos moradores }\end{array}$ & $\begin{array}{l}\text { Realizar nova visita aos pontos, } \\
\text { distribuir o material aos } \\
\text { moradores, e orientá-los sobre a } \\
\text { problemática do lixo no rio. }\end{array}$ & $\begin{array}{l}\text { Verificar se todas as equipes } \\
\text { fizeram as visitas e se } \\
\text { distribuíram o material. }\end{array}$ \\
\hline
\end{tabular}




\begin{tabular}{|l|l|l|}
\hline $\begin{array}{l}\text { E) Avaliação da } \\
\text { ocorrência de alguma } \\
\text { mudança em relação aos } \\
\text { resíduos sólidos no } \\
\text { córrego }\end{array}$ & $\begin{array}{l}\text { Realizar uma visita de } \\
\text { investigação, em um sábado no } \\
\text { período da manhã, nos pontos } \\
\text { definidos. }\end{array}$ & $\begin{array}{l}\text { Verificar se todas as equipes } \\
\text { fizeram as visitas e se } \\
\text { anotaram os tipos e } \\
\text { quantidades de resíduos } \\
\text { sólidos no córrego. }\end{array}$ \\
\hline $\begin{array}{l}\text { F) Avaliação do projeto } \\
\text { como um todo }\end{array}$ & $\begin{array}{l}\text { Relatar as atividades realizadas, } \\
\text { de forma organizada por grupo. }\end{array}$ & $\begin{array}{l}\text { Verificar se todos os grupos } \\
\text { relataram suas experiências. }\end{array}$ \\
\hline $\begin{array}{l}\text { G) Elaboração do relatório } \\
\text { final }\end{array}$ & $\begin{array}{l}\text { Elaborar o relatório final } \\
\text { utilizando os dados } \\
\text { apresentados por todos os } \\
\text { grupos no dia da avaliação do } \\
\text { projeto. }\end{array}$ & $\begin{array}{l}\text { Observar se todos os grupos } \\
\text { entregaram o relatório final à } \\
\text { professora no prazo } \\
\text { estabelecido. }\end{array}$ \\
\hline
\end{tabular}

Com a definição do planejamento do projeto e do cronograma das atividades que seriam desenvolvidas, as datas das visitas investigativas foram marcadas. Em todas as etapas do projeto a professora se mostrou muito atenta e colaborativa em orientar os grupos de alunos.

\section{MOLHANDO O DEDO DO PÉ}

Para o início das atividades propostas foi agendado um novo encontro, no qual os alunos trouxeram o mapa da cidade e cinco pontos para as visitas investigativas foram selecionados em função da facilidade de acesso ao córrego e da presença de edificações. Os pontos 1 e 5 localizavam-se em bairros periféricos nas regiões sul e norte, respectivamente, enquanto que os pontos 2,3 e 4, localizavam-se na região central da cidade. Todos os pontos coincidiam com locais onde havia pontes sobre o córrego, o que facilitou a observação. As regiões selecionadas são habitadas principalmente por moradores das classes sócio-econômicas $\mathrm{C}$ e $\mathrm{D}$, de acordo com o Instituto Brasileiro de Geografia e Estatística (IBGE, 2004).

Os alunos foram orientados sobre o procedimento para realizar uma estimativa dos tipos e da quantidade de resíduos sólidos presentes no córrego. Ficou definido que cada grupo realizaria uma observação dos resíduos depositados nas margens e na água do córrego, no período de uma hora, pela manhã, nos dois sábados destinados às visitas investigativas. Os alunos deveriam anotar o tipo e a quantidade do material, caracterizar o local com a descrição das moradias, ruas, presença de mata ciliar, além de registrar as condições do tempo. Outros aspectos do ambiente, como fluxo de transeuntes e de veículos, também foram registrados conforme o interesse de cada grupo.

Nos dias das visitas investigativas, a pesquisadora e a professora se revezaram no acompanhamento dos grupos nos pontos selecionados. Os alunos se mostraram muito interessados no desenvolvimento da observação, e se organizaram de forma 
colaborativa, sendo que todos os membros de cada grupo se revezaram nas atividades. Por iniciativa própria, os alunos levaram ao campo pranchetas, cadeiras dobráveis, sacos para coleta de lixo, lanche e água mineral.

Os grupos caracterizaram os locais de formas diferenciadas, alguns de modo muito simplificado, e outros com grande detalhamento do ambiente e das condições do tempo: "Local: Ponte da Rua João Batista Figueiredo Costa, Bairro Nova São João. Sábado: 26/05/2001. Horário: 10:00h às 11:00h. Tempo estável, com céu azul, sol, poucas nuvens e vento suave. Temperatura de $23^{\circ} \mathrm{C}$. O lugar onde se encontra o córrego é uma área urbana em expansão, tem poucas residências, na redondeza existem mais pontos comerciais e industriais. Em um lado da ponte não existe mata ciliar, mas esta é conservada na maioria da extensão do córrego. O movimento de automóveis e pessoas que passaram durante o período observado foi intenso, cerca de 13 pessoas, 59 carros, 12 motos e 6 caminhões." (Relatório Final do grupo responsável pelo ponto 1)

Os alunos encontraram uma grande diversidade de resíduos sólidos presentes na água e nas margens do córrego: bacia de alumínio, restos de cigarros, cabo de vassoura, cadeira, canetas, copos plásticos, embalagem de alumínio, folhas de papéis, garrafas plásticas, lata de óleo, latas de tintas, latinhas de alumínio, pisos cerâmicos, pneus, prato de isopor, restos de alimentos, sacos de ração, sacos plásticos, sofá, tábuas, televisão e tijolos. A quantidade de cada item observado variou de acordo com os pontos do córrego, sendo que uma concentração maior de resíduos foi encontrada na região central da cidade.

\section{ÁGUA PELO JOELHO}

Após as duas visitas investigativas, os alunos foram orientados a confeccionar um material informativo sobre a problemática do lixo no Córrego São João, para que fosse distribuído aos moradores de residências próximas aos pontos selecionados. A partir da experiência que os alunos tiveram com a observação dos resíduos sólidos nas margens e na água do Córrego, elaboraram panfletos explicativos. A professora e a pesquisadora não interferiram no processo, apenas realizaram a revisão do texto.

Conforme pode ser observado na Figura 1, apenas um grupo (último panfleto à direita) utilizou gravuras extraídas da Internet para ilustrar o material; os demais grupos optaram por desenhar a mão livre as ilustrações. No verso de cada panfleto, os alunos inseriram um pequeno texto informativo sobre o problema do lixo no rio. 

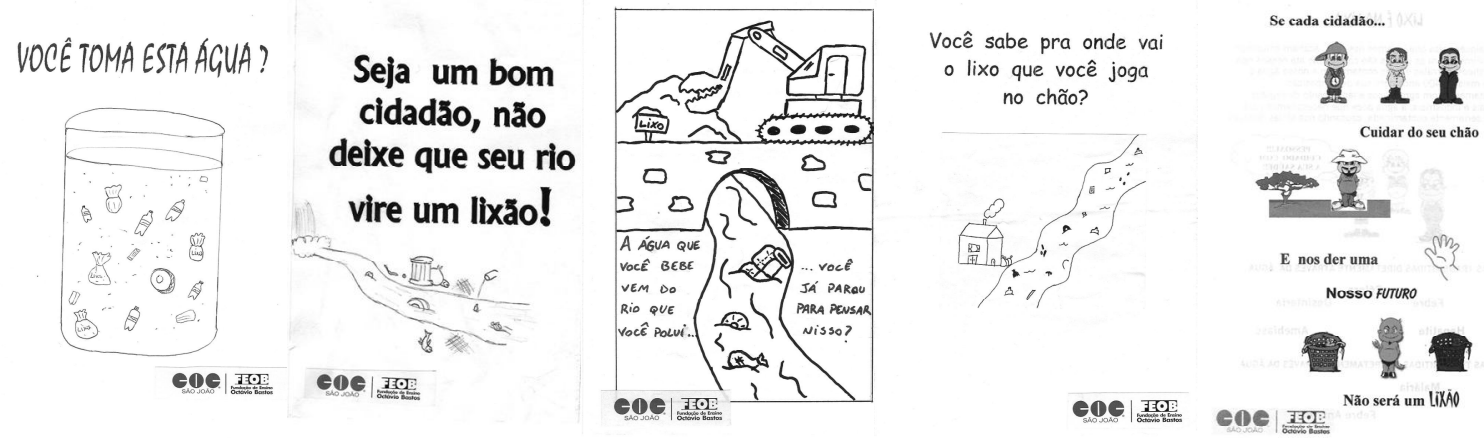

Figura 1: Panfletos informativos produzidos pelos grupos

Os panfletos informativos foram reproduzidos para distribuição a 20 moradores do entorno de cada um dos pontos do Córrego São João. Os alunos foram orientados para que a abordagem dos moradores fosse realizada de forma cordial e que fosse respeitada a vontade de cada morador em receber ou não o panfleto e a orientação.

A abordagem e a orientação aos moradores sobre a problemática dos resíduos sólidos no rio foi realizada sem a intervenção da pesquisadora ou da professora. De forma geral, os alunos tocavam a campainha ou batiam palmas em frente às residências e solicitavam para falar com os moradores, explicando que eram estudantes do Ensino Médio e que estavam fazendo um projeto de Educação Ambiental. Quando convidados a entrar, procediam às orientações na sala de estar; caso contrário, falavam com os moradores na porta da casa. As orientações eram iniciadas com a entrega do panfleto, no formato de uma breve explanação intermediada com algumas perguntas sobre o lixo no córrego.

No sábado posterior à distribuição dos panfletos e orientação aos moradores, os alunos retornaram aos pontos do córrego e realizaram nova observação dos resíduos sólidos presentes na água e nas margens. Todos os grupos relataram que não houve mudança significativa em relação ao lixo jogado nos pontos do Córrego São João após a atividade educativa.

\section{MERGULHO}

No encontro com os alunos para a avaliação do projeto como um todo, a pesquisadora solicitou que os relatos fossem gravados em áudio para que posteriormente pudessem integrar uma pesquisa acadêmica sobre a experiência. Todos 
concordaram em ter suas falas registradas pela pesquisadora. Os depoimentos voluntários foram identificados somente por um número, de 1 a 22 , correspondente à ordem da lista de chamada dos nomes dos alunos, sem distinção de gênero.

Cada um dos grupos relatou as atividades que realizaram e posteriormente, no formato de um debate, o projeto foi avaliado coletivamente. A pesquisadora mediou o debate colocando algumas questões sobre o desenvolvimento do projeto: $\mathrm{O}$ que vocês acharam do projeto como um todo? O que vocês perceberam ${ }^{4}$ com o projeto? O que vocês modificariam para um projeto futuro?

\section{O projeto como um todo}

Durante o debate, os alunos colocaram que consideraram o projeto muito positivo e proveitoso. Apesar da atividade de intervenção junto aos moradores não ter aparentemente surtido efeito em termos de redução da quantidade e dos tipos de resíduos sólidos presentes no Córrego São João, os alunos evidenciaram aspectos favoráveis do projeto para a própria formação.

Os depoimentos de alguns alunos enfatizaram a dimensão prática do projeto, a possibilidade de atuar em outros espaços além da sala de aula e de observar o problema ambiental in loco.

Na minha opinião, a gente conseguiu ver tudo que acontece aqui no rio de perto. Eu acho que o projeto ajudou para saber que tem muita gente que não sabe que não pode jogar lixo no rio. (Aluno 2)

Eu gostei de sair na cidade. Nunca tinha andado de ônibus. Só de ônibus de viajar. Gostei muito porque eu vi que tem um monte de gente que vive de forma diferente, que tem outras idéias. Também gostei de trabalhar na minha equipe. Ninguém desrespeitou nenhum morador. A gente viu que as pessoas podem ser mais pobres, mas que a gente tem muito o que aprender com elas. Eu gostei das histórias que um senhor contou sobre a cidade e das mudanças que aconteceu (sic!) com o passar do tempo e com o crescimento de São João. (Aluno 3)

Eu achei importante que meus colegas respeitaram os outros. Ninguém ficou tirando sarro das pessoas mais simples. As

\footnotetext{
${ }^{4}$ Em relação ao conceito de percepção, adotamos a visão defendida por Del Rio e Oliveira (1996), que caracteriza a percepção como um processo de cognição em que os procedimentos mentais se realizam mediante o interesse ou a necessidade de estruturar a interface individual com a realidade e o mundo, selecionando as informações percebidas, armazenando-as e conferindo-lhes significado.
} 
professoras trabalharam bem com a gente antes. Essa diferença e o respeito foi muito legal. Eu adorei. (Aluno 5)

O que eu mais gostei foi de poder conhecer a cidade. Fui a lugares que eu nunca iria se não fosse pelo projeto. A gente viu um monte de coisas que eu nem sabia que existia. Foi massa [legal] que uma senhora bem velha pediu para a gente entrar na casa dela e tomar café com bolo. Bem legal porque a gente foi bem recebido. A gente ficou junto com a população. Viu os problemas deles e também as alegrias. Uma forma diferente de ver as coisas. Eu cresci com isso. Contei para os meus pais, mas acho que eles não entenderam direito porque eles também precisam ver isso tudo. Não adianta contar. Tem que ver. (Aluno 11)

Eu achei legal por dois motivos. Um que a gente pôde fazer alguma coisa prática e não ficar só vendo as coisas na escola, longe da realidade. Outro porque fiz coisas que nunca tinha feito antes. Nunca tinha pensado de usar um sábado para fazer coisas pelo meio ambiente e foi legal. A gente ficou mais amigo e viu coisas diferentes. (Aluno 20)

Com o projeto, os alunos tiveram a oportunidade de vivenciar experiências nunca antes realizadas, como andar de ônibus, trabalhar em equipe, trabalhar aos sábados, conhecer a casa e conversar com pessoas de baixa renda. Essas vivências aguçam o interesse do aluno pelo projeto, uma vez que este é o meio através do qual se torna possível realizar essas atividades inusitadas, estabelecendo-se assim um processo de contínuo estímulo para o desenvolvimento do projeto.

A satisfação dos alunos ao desenvolver uma prática em campo e realizar atividades novas possibilita uma postura empática (FALCONE, 1999) em relação ao projeto. Nesse sentido, Seniciato e Cavassan (2004) apontam que o ato de aprender ou compreender os fenômenos da realidade é reconfortante e satisfatório para os alunos. Desse modo, todas as emoções e sensações surgidas durante a aula de campo podem auxiliar na aprendizagem dos conteúdos, à medida que os alunos recorrem a outros aspectos de sua própria condição humana, além da razão, para compreenderem os fenômenos.

Ao sair do ambiente escolar, os alunos se depararam com a realidade da cidade não apenas no aspecto ambiental e geográfico enfocado inicialmente pelo projeto, mas principalmente o social. Ao abordar os moradores, os alunos se sentiram responsáveis por informar sobre a problemática do lixo de forma respeitosa, levando em consideração a forma de vida, o grau de escolaridade e as dificuldades econômicas das pessoas de 
baixa renda. Esse respeito ao outro ficou evidente na frase do Aluno 3: A gente viu que as pessoas podem ser mais pobres, mas que a gente tem muito o que aprender com elas. Dessa forma, os alunos além de visualizarem e respeitarem a diferença sócio-econômica entre eles e os moradores, também compreenderam que é possível aprender com essas pessoas.

Para Jacobi (2003), o principal eixo de atuação da educação ambiental deve buscar, acima de tudo, a solidariedade, a igualdade e o respeito à diferença através de formas democráticas de atuação baseadas em práticas interativas e dialógicas. Provavelmente, ao possibilitar o contato direto dos alunos com os moradores do entorno do Córrego São João, o projeto de Educação Ambiental se constituiu como ponte de acesso desses alunos à realidade, e ao vivenciar a realidade na relação com o diferente, foi possível agregar dimensões humanitárias ao próprio projeto e à vida dos alunos.

$\mathrm{O}$ trabalho em equipe constituiu-se uma oportunidade para que os alunos pudessem se aproximar mais dos colegas, escutá-los, compartilhar idéias e melhorar as relações interpessoais. Foi possível perceber que os membros do grupo tomaram como referência o cronograma estabelecido de forma coletiva em sala de aula, mas adicionaram elementos próprios na relação de convivência com os colegas e com os moradores, no sentido de desenvolver as atividades respeitando as opiniões de todos os envolvidos.

Sobre a importância do trabalho em grupo em projetos de Educação Ambiental, as autoras Reigada e Tozoni-Reis (2004) colocam que à Educação Ambiental cabe a tarefa, entre outras coisas, de restabelecer a convivência no grupo, e que o trabalho em grupo é necessário para desenvolver a capacidade de participação e inserção dos indivíduos no meio social.

\section{Percepções}

Os alunos perceberam com o desenvolvimento do projeto, que o problema dos resíduos sólidos no Córrego São João é complexo. Nas falas dos alunos, fica evidente que a visão simplista de que para acabar com esse problema basta informar a população para não jogar lixo no chão, foi substituída por uma visão mais ampla, que passou a englobar a dimensão sócio-cultural. Vivenciando a realidade e entrando em contato com a população, os alunos puderam não apenas observar o fenômeno "lixo no rio", mas estabelecer relações sobre os motivos que levam os moradores a descartar resíduos sólidos no córrego e as conseqüências desse ato. 
As pessoas não têm noção de que poluindo a água elas vão acabar se prejudicando também. Parece que não enxergam que as enchentes são uma conseqüência do que eles mesmos fazem. Uma senhora falou que a casa dela, que fica do lado do córrego, sempre inunda com a chuva e ela mesma ao invés de colocar o lixo para o caminhão de coleta pegar, joga no rio. Aí não tem jeito. (Aluno 2)

Eu não sabia que tinha tanto córrego em São João. Não tem mais mata ciliar. Ninguém nem sabe o que é isso. Eu falei com um morador e ele achava que o córrego devia ser desviado, não passar mais pela cidade porque atrapalha quando chove. Vai vendo. Ele que está morando em cima do rio e quer tirar o rio porque com a chuva entope tudo e acaba alagando a casa dele. (Aluno 18)

Eu não sabia que ainda tinha gente aqui na cidade que não tinha esgoto. Tem várias casas que o esgoto sai direto para o rio. Ué, se o esgoto sai direto pro rio, porque eles não podem jogar outras coisas lá também? É outra realidade. (Aluno 13)

A gente viu um cara que jogou um sofá no córrego. Não fui perguntar para ele o que ele achou, o que estava pensando, mas devia ter ido sim. Eu nunca jogaria um sofá no rio. (Aluno 14)

Uma ocorrência comum na cidade de São João da Boa Vista é o alagamento de ruas e avenidas nas regiões próximas ao Córrego São João. Em notícia de 15 de janeiro de 2007, a Metsul Meteorologia destacou em sua página na Internet ${ }^{5}$ que "Em São João da Boa Vista, as águas do Córrego São João inundaram cerca de sessenta imóveis”, o que comprova que mesmo nos dias atuais, as enchentes tem sido um problema no município.

Essa problemática das enchentes foi detectada pelos alunos. $\mathrm{Na}$ reunião de avaliação geral do projeto foi possível verificar pelos relatos que eles possuem a percepção de que os resíduos sólidos, quando jogados no córrego, se alojam nas margens e entopem as tubulações, dificultando o fluxo das águas; e quando chove, o escoamento da água da chuva fica comprometido devido a quantidade de resíduos sólidos presentes no córrego. Ao desenvolver o projeto, os alunos passaram a lidar com

\footnotetext{
${ }^{5}$ http://metsul.com/secoes/visualiza.php?cod_subsecao=29\&cod_texto=502
} 
uma questão social, das razões que levam os moradores a jogar os resíduos sólidos no córrego.

Ao exemplificar que uma senhora jogou lixo no córrego ao invés de encaminhar para a coleta e relacionar essa atitude à enchente que inunda a casa dessa mesma senhora, o aluno demonstra uma compreensão de que a coleta urbana de lixo domiciliar, disponível em todos os bairros de São João da Boa Vista, não é suficiente para modificar o hábito daquela senhora em dispensar o lixo no córrego.

A percepção sobre a ausência de mata ciliar em pontos do centro da cidade em que o córrego foi pavimentado, e sobre a idéia do morador de querer desviar o córrego do centro do município, remete a um entendimento geral sobre a complexidade da questão.

Os moradores que não possuem coleta de esgoto consideram o córrego local apropriado ao descarte de resíduos, e assim, vivenciam uma realidade diferente daqueles que possuem saneamento básico e têm outra compreensão acerca dos malefícios de se jogar lixo no rio. Ao perceber essa dinâmica, o aluno passa a valorizar o modo de vida das pessoas envolvidas no projeto e a ampliar sua visão de mundo, considerando aspectos sociais e culturais na determinação de um problema ambiental.

Algumas situações absurdas, como a de um sofá e de uma televisão lançados no córrego, foram vivenciadas pelos alunos. Ao se sentirem indignados com o fato, os alunos passaram a questionar os motivos de alguém praticar esse tipo de ação, uma vez que eles afirmam que não a fariam. Nesse sentido, seria adequado explorar se a funcionalidade dos objetos ou o tamanho dos mesmos determinam a reprovação, pelos alunos, da atitude de um morador. Isso porque, provavelmente, itens de pequenas dimensões ou considerados inúteis pelos alunos não desencadeiam um impacto visual nas mesmas proporções do sofá e da televisão.

Outro aspecto que foi evidenciado pelos alunos é a necessidade de compartilhamento de responsabilidades. $\mathrm{Na}$ voz dos discentes, não basta ter o varredor de rua e a atuação do poder público na limpeza urbana, visto que é fundamental a educação da população sobre o problema.

Eu acho que não é só quem mora perto do córrego que não sabe dos problemas que o lixo no rio causa. Eu nunca jogo papel no chão, mas meus amigos de vez em quando jogam. Com o projeto eu vi que alguns pararam de jogar. Parece que mudaram de opinião. Não precisa ter só o varredor de rua. 
Precisa também, mas não só ele. Cada pessoa tem que ser educada para resolver esse problema. (Aluno 6)

Eu percebi que não podemos ficar esperando. Achando que alguém como o prefeito tem que limpar o rio. Não dá. Tem que ensinar os moradores que eles não podem ficar jogando lixo onde quiser (sic!). Senão um limpa e outro suja. Fica sempre sujo. (Aluno7)

Os alunos reconheceram que o projeto foi importante no sentido de possibilitar realizar algo prático relacionado à Educação Ambiental. Assim, os participantes se sentiram co-responsáveis pelo problema "Lixo no Córrego São João" e se viram incluídos como cidadãos e dotados de potencial para realizar ações em prol da solução dessa problemática, sem ficar apenas "esperando" que algo aconteça.

$\mathrm{O}$ projeto estimulou alguns alunos a se interessarem em atuar junto a uma Organização Não-Governamental Ambiental de São João da Boa Vista.

Eu gostei porque conheci outras pessoas da minha idade que vivem de um jeito diferente, mas que também tem consciência do lado ambiental. Tem um cara que tem a minha idade e que está fazendo parte de uma $\mathrm{ONG}^{6}$ no bairro dele para falar para as pessoas catarem o lixo e não jogarem no chão ou no rio. Ele ficou famoso no bairro dele porque agora todos conhecem ele (sic!) como o Rafa da ONG. E é legal porque ele também estuda as mesmas coisas que a gente, mas está fazendo alguma coisa. A gente também está fazendo com esse projeto mas é muito pouco. Com a ONG ele faz todo dia e não só espaçado. Eu até fiquei empolgado e acho que vou entrar na ONG também. Sei lá acho que a escola podia ir falando para a gente como que a gente pode ajudar, como participar com as pessoas para mudar alguma coisa. Eu acho que tem muita gente que fala que tem que fazer isso, fazer aquilo mas nunca saiu da casa ou do trabalho para ver as coisas na realidade. Eu gostei de fazer o projeto porque vi na real. (Aluno 19)

Ao pontuar que as pessoas precisam opinar sobre os problemas ambientais e suas possíveis soluções de forma consciente, tendo vivido a realidade, o aluno critica a simplificação das questões relativas ao meio ambiente porque, ele próprio através do projeto, pôde entrar em contato com a população e observar atentamente o problema do lixo, verificando que inúmeros fatores o determinam, não havendo uma solução imediatista e fácil para o problema.

\footnotetext{
${ }^{6}$ Organização Não-Governamental Grupo Ecológico Curupira
} 
De forma mais abrangente, a pesquisadora Mota (2005), afirma que o problema do lixo conjuga aspectos técnicos, econômicos, ambientais, culturais, políticos e sociais que não podem ser tomados de forma isolada, e que nenhuma proposta que considere apenas um desses aspectos será boa o suficiente para resolver a questão.

\section{Para o futuro}

No encontro final, todos os alunos colocaram que teriam interesse em participar novamente de um projeto semelhante no futuro. Quando questionados sobre o que mudariam no projeto, visto que não ocorreu mudança significativa nos resíduos sólidos jogados no córrego após a intervenção, os alunos foram unânimes em reconhecer que tinham sido ingênuos em acreditar que poderiam modificar a situação somente entregando panfletos e orientando os moradores. Com isso, os discentes demonstram uma compreensão da problemática sócio-ambiental e das limitações das atividades pontuais junto à população.

Especificamente sobre os panfletos, um grupo comentou que a estratégia de abordagem dos moradores deveria ser diferente, utilizando apenas imagens, em função do analfabetismo.

Eu acho que o panfleto não adiantou nada porque somente um morador que eu entreguei sabia ler. $O$ resto só podia ver a figura. Quer dizer, eu não perguntei se ele não sabia ler, claro, mas ficou na cara. Acho que o bom mesmo é uma conversa. A gente acha que todo mundo é igual à gente, mas não é não. (Aluno 19)

Vários alunos mostraram interesse em ampliar o projeto, dar continuidade às atividades e transformá-lo em um programa permanente de Educação Ambiental que poderia ser assumido pelo governo municipal.

Eu acho que tinha que ter um programa da prefeitura de educação ambiental para ensinar porque que não pode jogar lixo no rio. Eu só aprendi aqui. Não tinha idéia de todos os problemas para o meio ambiente que isso pode levar. E também acho que tem um monte de gente que não sabe. É ignorância. Se você souber, e mudar de opinião fica mais fácil não fazer. (Aluno 6) 
Os próprios alunos sugeriram idéias e formas para levar a proposta à prefeitura, através dos vereadores da Câmara Municipal, mostrando conhecimento sobre os caminhos para se exercitar a cidadania e promover políticas públicas.

\section{EMERSÃO}

O projeto de Educação Ambiental "Lixo no Córrego São João" foi iniciado com o propósito de propiciar aos alunos uma vivência prática em campo na temática do lixo. Com a participação democrática dos alunos, da professora e da pesquisadora, o projeto ganhou novos significados e se tornou um meio de integração dos participantes, de discussão e de mudança de valores.

A avaliação sugerida no formato de um relatório final foi considerada na disciplina, no entanto, como todos os grupos foram avaliados de forma muito positiva pelo interesse na realização do projeto e reflexão coletiva dos resultados, o relatório pareceu-nos um instrumento avaliativo válido, mas somente complementar ao debate estabelecido com os alunos. As pesquisadoras Tomazello e Ferreira (2001) acreditam ser importante não só avaliar como também superar a visão simplista de avaliação, pois os resultados da avaliação de um projeto de Educação Ambiental devem sinalizar, por meio da compreensão, da reflexão e do diálogo entre seus atores, os elementos que consistiriam na autêntica melhoria do programa.

Como o projeto foi compartilhado com os alunos desde sua concepção até a avaliação final, com etapas bem definidas no cronograma, os alunos puderam se planejar e organizar as atividades que seriam realizadas, além de dedicar tempo suficiente para a elaboração e discussão das mesmas. Com isso, o interesse em se manter ativo e participante no projeto foi grande.

Ao utilizarmos um tema gerador de discussões ambientais sugerido pelos próprios alunos, levamos em consideração o interesse dos discentes em estudar e propor soluções para um problema ambiental real presente no cotidiano.

Para Tonozi-Reis (2006), os temas ambientais locais e significativos têm que ser tomados como ponto de partida para análises críticas da realidade sócio-ambiental, e como geradores da formação crítica se constituem como importante diretriz metodológica para a Educação Ambiental. Na perspectiva da Educação Ambiental crítica, transformadora e emancipatória, os temas ambientais não podem ser conteúdos curriculares no sentido que a pedagogia tradicional trata os conteúdos de ensino. A educação crítica e transformadora exige um tratamento mais vivo e dinâmico dos 
conhecimentos, que não podem ser transmitidos de um pólo a outro do processo, mas apropriados e construídos de forma dinâmica, coletiva, cooperativa, contínua, interdisciplinar, democrática e participativa, pois somente assim pode contribuir para o processo de conscientização dos sujeitos para uma prática social emancipatória, condição para a construção de sociedades sustentáveis.

No sentido de promover um projeto de Educação Ambiental que pudesse focar os problemas ambientais e, simultaneamente, induzir mudanças de valores e práticas nos alunos, o papel da professora e da pesquisadora foi importante para organizar coletivamente as etapas de trabalho, promover discussões e estimular a autonomia dos alunos tanto na solução de problemas logísticos quanto na responsabilidade de expressar suas idéias e sensações.

O contato com a sociedade e a observação dos problemas ambientais de forma global, incluindo os aspectos sociais, econômicos e culturais da população, possibilitou uma extensa reflexão sobre a problemática do lixo. A tomada de consciência sobre os inúmeros fatores que contribuem para a perpetuação desse problema decorreu da vivência prática e do diálogo com os moradores, dimensões que se mostraram imprescindíveis para a sensibilização dos alunos ao longo do projeto. Nessa linha de pensamento, Marin e colaboradores (2003) colocam que a sensibilização ambiental não se dá, única e exclusivamente pela via racional, pelas construções conceituais, mas através de um amplo caminho onde se cruzam imaginação, contemplação e reflexão.

Geralmente, somente as disciplinas de Geografia e Biologia abordam o tema Meio Ambiente no currículo, mesmo se tratando de um tema transversal proposto nos Parâmetros Nacionais Curriculares (BRASIL, 1997) que deveria ser trabalhado de forma interdisciplinar, envolvendo todas as áreas do conhecimento. Aqueles que trabalham na escola ou convivem com a comunidade escolar, pública ou privada, sabem das várias dificuldades para se planejar e estruturar projetos curriculares integrados (HERNÀNDEZ, 1998), seja pela falta de tempo para discussões em grupo, determinações de ordem política, disposição, preparo e limitações teóricometodológicas dos professores e orientadores pedagógicos. Sendo assim, cabe questionar se experiências isoladas dessas disciplinas, com projetos que englobam elementos apontados por muitos pesquisadores da área como fundamentais para a Educação Ambiental crítica e emancipatória (GUIMARÃES, 2004; LOUREIRO, 2003) não podem se configurar em um palco para o início de um diálogo com outras disciplinas, que aos poucos possa vir a envolver mais professores e alunos? O que é 
mais significativo? Desenvolver projetos isolados em disciplinas cujos professores e alunos se dispõem a fazê-los ou não fazê-los porque não há o envolvimento de outras disciplinas nem a consolidação de um currículo unificado?

De acordo com Pestana (2007), é numa escola preparada para tratar das questões ambientais e voltada para a formação de cidadãos críticos, reflexivos e, plenamente, conscientes de seus direitos e deveres que se encontra o ambiente ideal para o desenvolvimento e formação de valores, indo além dos conteúdos aplicados em sala de aula, fornecendo mais que informações e conceitos, valorizando comportamentos, experiências e habilidades que possam favorecer o trabalho que o tema propõe dentro do currículo e nas práticas cotidianas de todos.

No artigo "Debatendo os Desafios da Educação Ambiental", a pesquisadora Michèle Sato (2001) aponta que em diversos trabalhos publicados, apresentados ou informados na área da Educação Ambiental, há uma tendência em se considerar somente os bons resultados, frutos de uma trajetória que parece ter sido traçada linearmente. Na experiência que relatamos, os resultados satisfatórios evidenciados não foram alcançados com o projeto e sim, por meio do projeto. Como a atividade de intervenção proposta não deflagrou modificações de conduta dos moradores em relação ao lixo no córrego, poderíamos ter considerado o projeto, por essa ótica, de pouco êxito. No entanto, os próprios alunos que pensaram estar desenvolvendo uma atividade para educar os moradores sobre a problemática do lixo foram alvo do projeto, visto que por meio deste, puderam se perceber como cidadãos pertencentes a uma coletividade.

A Educação Ambiental promove não apenas a mudança de hábitos e comportamentos do indivíduo, mas a construção de uma cidadania plena, que extrapola os direitos e deveres garantidos por lei, para que seja formulado um novo modelo de sociedade, mais igualitária e que proporcione melhor qualidade de vida a todos (JACOBUCCI, 2006).

A Educação Ambiental como formação e exercício de cidadania refere-se a uma nova forma de encarar a relação do homem com a natureza, baseada numa nova ética, que pressupõe outros valores morais e uma forma diferente de ver o mundo e os homens, e assim deve ser vista como um processo de permanente aprendizagem que valoriza as diversas formas de conhecimento e forma cidadãos com consciência local e planetária (JACOBI, 2003). 
Essa formação se relaciona com a Educação Ambiental, no sentido de consolidar o exercício da cidadania para atuação em todas as esferas da sociedade e em todas as questões que envolvem a existência humana, inclusive, e não somente, o meio ambiente.

\section{BANHO TOMADO}

O projeto de Educação Ambiental "Lixo no Córrego São João" foi enfocado metaforicamente como um banho de cidadania porque as concepções prévias, de quem vê de fora o problema ambiental, foram substituídas por visões ampliadas de mundo, nas quais os alunos passaram a considerar as dimensões ambientais, sociais, econômicas, políticas e culturais envolvidas no processo, e a expressar de forma responsável essas visões.

Ao despir as idéias simplistas sobre os problemas ambientais, é possível pensar que as soluções para esses problemas também são complexas, pois envolvem a mudança de valores das pessoas que convivem diariamente com o problema e que contribuem para sua perpetuação, demandando planejamentos estratégicos de gestão ambiental e uma Educação Ambiental plena e continuada.

\section{AGRADECIMENTOS}

Agradecemos à professora de Geografia Raquel Atalla Murr pela simpática colaboração na realização da pesquisa e a Lourdes Jaine Franco Carvalho pela revisão do texto.

\section{REFERÊNCIAS BIBLIOGRÁFICAS}

BORTOLOZZI, Arlêude; PEREZ FILHO, Archimedes. Diagnóstico da Educação Ambiental no Ensino de Geografia. São Paulo: Cadernos de Pesquisa, 109: 145-171, 2000.

BRASIL, Ministério da Educação. Parâmetros curriculares Nacionais. Brasília: MEC, 1997.

DEL RIO, Vicente; OLIVEIRA, Lívia (Orgs.). Percepção Ambiental: A Experiência Brasileira. São Carlos: Studio Nobel, Editora da UFSCar, 1996.

FALCONE, Eliane. A avaliação de um programa de treinamento da empatia com universitários. São Paulo: Revista Brasileira de Terapia Comportamental e Cognitiva, 1: 23-32, 1999.

FERNANDES, Roosevelt da Silva; VIEGAS, Regina; GUANANDY, Jessica Vicente. Avaliação do Perfil de Cidadania Ambiental de Estudantes do Ensino Médio-Técnico 
do CEFET-RJ. Rio Grande: Revista Eletrônica do Mestrado em Educação

Ambiental, 17: 195-213, 2006.

FERREIRA, Manuela Malheiro; MIRANDA, Branca Margarida; ALEXANDRE, Fernando. Educação para a cidadania: tendências actuais. Anais do Active Citizenship, Sustainable Development and Cultural Diversity, 1-8, 2002.

GUIMARÃES, Mauro. A formação de educadores ambientais. Campinas: Papirus, 2004.

GUIMARÃES, Mauro; VASCONCELLOS, Maria das Mercês Navarro. Relações entre educação ambiental e educação em ciências na complementaridade dos espaços formais e não formais de educação. Curitiba: Educar, 27: 147-162, 2006.

HERNÀNDEZ, Fernando. Transgressão e mudança na educação: os projetos de trabalho. Porto Alegre: Artmed, 1998.

IBGE (Instituto Brasileiro de Geografia e Estatística) Resultados da Amostra do Censo Demográfico 2000 - Malha municipal digital do Brasil: situação em 2001.

Rio de Janeiro: IBGE, 2004.

JACOBI, Pedro. Educação Ambiental, Cidadania e Sustentabilidade. São Paulo: Cadernos de Pesquisa, 118: 189-205, 2003.

JACOBUCCI, Daniela Franco Carvalho. A Formação Continuada de Professores em Centros e Museus de Ciências no Brasil. Campinas, 2006. Tese de Doutorado.

Faculdade de Educação - Universidade Estadual de Campinas.

LOUREIRO, Carlos Frederico Bernardo. O movimento ambientalista e o pensamento crítico: uma abordagem política. Rio de Janeiro: Quartet, 2003.

MARIN, Andréia Aparecida; OLIVEIRA, Haydée Torres; COMAR, Vito. A Educação Ambiental num Contexto de Complexidade do Campo Teórico da Percepção. Caracas:

Interciência, 28 (10): 616-619, 2003.

MOTA, Adriana Valle. Do Lixo à Cidadania. Rio de Janeiro: Democracia Viva, 27: 38, 2005.

PESTANA, Ana Paula da Silva. Educação Ambiental e a Escola, uma ferramenta na gestão de resíduos sólidos urbanos. Novo Hamburgo: Educação Ambiental em Ação, 21: 506, 2007.

REIGADA, Carolina; TOZONI-REIS, Marilia Freitas de Campos. Educação Ambiental para Crianças no Ambiente Urbano: Uma Proposta de Pesquisa-Ação. Bauru: Ciência \& Educação, 10, (2): 149-159, 2004.

SATO, Michèle. Debatendo os desafios da educação ambiental. Rio Grande: Revista Eletrônica do Mestrado em Educação Ambiental, 1: 14-33, 2001. 
SENICIATO, Tatiana; CAVASSAN, Osmar. Aulas de Campo em Ambientes Naturais e Aprendizagem em Ciências - Um Estudo com Alunos do Ensino Fundamental. Bauru: Ciência \& Educação, 10 (1): 133-147, 2004.

SILVA-SÁNCHEZ, Solange Santos. Cidadania ambiental: novos direitos no Brasil. São Paulo: Humanitas, FFLCH/USP: Annablume, 2000.

TOMAZELLO, Maria Guiomar Carneiro; FERREIRA, Tereza Raquel das Chagas. Educação Ambiental: Que Critérios Adotar para Avaliar a Adequação Pedagógica de seus Projetos? Bauru: Ciência \& Educação, 7 (2): 199-207, 2001.

TOZONI-REIS, Marília Freitas de Campos. Temas ambientais como "temas geradores": contribuições para uma metodologia educativa ambiental crítica, transformadora e emancipatória. Curitiba: Educar, 27: 93-110, 2006. 